\title{
We're Pleased to be On-Board
}

\author{
Barak Wolff, NREMT-B, MPH*
}

On behalf of the National Association of State Emergency Medical Services (EMS) Directors (NASEMSD) [United States] I wish to express our pride and pleasure in becoming associated with Prehospital and Disaster Medicine. In the past year my colleagues and I have observed the development of this new journal with both enthusiasm and a strong sense that the existence of a scientifically based, peer-reviewed journal dedicated to emergency medical care "in the field" was long overdue.

In future issues, the National Association of State EMS Directors will be describing its activities and publishing its resolutions and position papers in Prehospital and Disaster Medicine. In addition, selected association members will serve on the Editorial Board and contribute papers on a regular basis.

\section{What Is NASEMSD?}

The National Association of State EMS Directors is a non-profit organization comprised of the EMS directors of each state, the District of Columbia, and the United States Territories. The association was formed in 1980 to provide leadership and support for the development of effective EMS systems nationwide, to foster communication among the state directors and with state and federal officials, and to represent the specific needs and opinions of state EMS directors on national issues.

Our goals are to:

1. Promote the orderly development of coordinated EMS systems across the United States;.

2. Promote uniform, high quality care for acutely ill and injured patients.

3. Provide a forum for the exchange of information and the discussion of concerns common among state EMS Directors.

4. Facilitate interstate cooperation in areas such as patient transfer, communications, and legal recognition of EMS personnel.

5. Disseminate pertinent information to our members and others.

6. Maintain ongoing and effective liaison with state and national governments, professional organizations, and other appropriate public and private entities.

7. Improve the quality and efficiency of state EMS program administration.

8. Enhance the professional knowledge, skills, and abilities of state EMS directors and staff.

9. Encourage research and evaluation in all areas of EMS; and

10. Serve as a permanent, national, advocacy group for EMS.

We are confident that our association with Prehospital and Disaster Medicine most certainly will help us achieve these goals.

\section{Activities of NASEMSD}

\section{The Sam Channel National EMS Clearinghouse}

Named after the former assistant director of West Virginia's EMS Office-a dedicated, energetic and creative man-the Clearinghouse was formed in 1985 as a vehicle for information gathering and exchange. Its use has allowed us to improve networking between states relative to

\footnotetext{
* President, National Association of State EMS Directors

The Council of State Governments in Lexington, Kentucky, provides staff support and administrative services to NASEMSD and manages the Sam Channel National EMS Clearinghouse.

For further information about any of the items mentioned contact NASEMSD, c/o Ellen Hume, Council of State Governments, P.O. Box 11910, Iron Works Pike, Lexington, KY 40578;

(606) 231-1903.* President, National Association of State EMS Directors
} 
the structure and organization of offices and programs, as well as to compile and share what we know about EMS in our respective states and, thus, in the aggregate, what we know about EMS in the United States. The Clearinghouse functions as an EMS library, a survey and research center, and a source of publications and briefs relative to state EMS programs and activities. In recent years, the automation and expansion of our data bases has been supported by the EMS Office of the National Highway Traffic Safety Administration (NHTSA). Also, NASEMSD has a cooperative relationship with the Charles McC. Mathias, Jr., National Study Center for Trauma and EMS and is a founding member of the recently formed Coalition for EMS and Injury Control Information Management.

\section{Publications}

A major priority of NASEMSD is a biennial survey of state EMS programs with the subsequent publication of monographs on the following topics: 1) state EMS office structures and responsibilities; 2) transportation systems and facilities; communication systems and disaster preparedness; 3) personnel training and licensure; and 4) public information and education. In cooperation with the National Council of State EMS Training Coordinators, the Clearinghouse also distributes national, standard curricula for First Responder, EMT-Basic, and Paramedic Refresher Training Programs. Finally, published surveys of state EMS laws and regulations, trauma care systems, licensure fees, and the like also are available.

\section{Coordination and Advocacy}

The NASEMSD has undertaken several projects to improve relationships between EMS organizations and with related-interest groups. With support from NHTSA, mini-grants were awarded to several states to develop and enact prevention strategies by EMS providers working together with traffic safety groups. Currently, in an effort to improve EMS communications, NASEMSD is working to achieve a consensus among various groups with diverse interests, and, thus, to develop the ability to approach the Federal Communications Commission with a unified voice. Finally, we have joined with others to support the development and passage of the national EMS and trauma care legislation now before the U.S. Congress. The education of legislators about the importance of these initiatives is one of our top priorities.

\section{A Look Ahead}

In spite of my natural inclination towards optimism, I truly believe that EMS in the United States is in a stronger, more clearly articulated, and visible position than it was a decade ago. As we entered the $1980 \mathrm{~s}$, federal leadership and funding were vanishing. The challenge to states and local areas to pick up the slack was met in a mixed fashion, and has led to uneveness and, in some cases, variability in both the availability and quality of EMS not only from one state to another, but even between neighboring communities.

However, in the late 1980s there has occurred a coalescence of interest and leadership manifesting efforts to identify problems in EMS and trauma care systems, and to seek solutions at all levels. The American Society for Testing Materials (ASTM) process to reach consensus on various EMS standards, albeit imperfect and without the support of several key medical groups, has accomplished some excellent progress in pooling our best knowledge on what "ought to be." The American College of Emergency Physicians has broadened its active EMS Committee to include representatives from other key national organizations. The emergence of the National Association of EMS Physicians as an eclectic, professional organization to meet the needs of all those interested in improving medical control of EMS also has furthered the cause.

As part of the broadly based concerns relative to various aspects about the overall health care delivery system in the United States, there have been a series of new, national-level, EMS initiatives proposed in Congress to deal with trauma care, rural EMS, ambulance reimbursement, emergency response personnel protection, and the like. Working together with our strong and pervasive grass roots constituency, I am optimistic that we can reestablish an appropriate federal participation, leadership, and funding for EMS to assist in the development of elements so sorely needed-research and demonstrations, technical assistance and support, and new incentives and direction to state and local efforts. It has become clear that EMS is one of the true, basic "safety net" services within the U.S. health care system. The 1990s promise to be a decade during which at least a reasonable level of access to EMS systems for all citizens is ensured and progress will continue to better define and achieve excellence throughout EMS.

Again, NASEMSD is pleased to be on-board with Prehospital and Disaster Medicine and we look forward to a long and prosperous relationship that will improve ultimately both our understanding of and the quality of prehospital and disaster medicine. 